\title{
Clinical and radiological outcome of distal femoral fractures treated by distal femoral locking compression plate
}

\author{
B. L. Khajotia, Vikrant Shekhawat*, Shakti Chauhan, Sunil Bhatiwal
}

Department of Orthopaedics, Sardar Patel Medical College, Bikaner, Rajasthan, India

Received: 10 June 2019

Revised: 19 August 2019

Accepted: 29 August 2019

*Correspondence:

Dr. Vikrant Shekhawat,

E-mail: vikrant_shekhawat007@yahoo.com

Copyright: () the author(s), publisher and licensee Medip Academy. This is an open-access article distributed under the terms of the Creative Commons Attribution Non-Commercial License, which permits unrestricted non-commercial use, distribution, and reproduction in any medium, provided the original work is properly cited.

\begin{abstract}
Background: Distal femoral fractures represent a challenging problem in orthopaedic practice. Open reduction with internal fixation has replaced previous trends of closed conservative management and external fixation. Distal femoral locking compression plate (DF-LCP) provides both locking and compression screw fixation of the femur shaft. This study was conducted to assess the clinical and radiological results of distal femoral fractures treated with DF-LCP.

Methods: It was a prospective study on 90 cases. Fracture patterns AO type A and $\mathrm{C}$ were considered. Lateral approach was used as standard surgical technique. The total follow up period was 6 months .Functional and radiological results were evaluated using Neer's score.

Results: The series consisted of 64 males and 26 female patients with mean age 40.56 years. Road traffic Accident $(68 \%)$ was the commonest mode of injury. Most were closed fractures. Wound infection was seen in 4 patients. Average flexion at knee joint was $117^{\circ} .100 \%$ union rate was observed with an average union time of 14.3 weeks. NEER's score was excellent in 44, good in 32, fair in 10 cases and poor in 4 cases.

Conclusions: DF-LCP is an important armamentarium in treatment of distal femur fractures especially when fracture is closed, severely comminuted and in case of osteoporosis.
\end{abstract}

Keywords: Distal femoral locking compression plate, Internal fixation, Distal femur fracture

\section{INTRODUCTION}

In the last few decades, rapid industrialization has brought both comforts and catastrophe like road traffic accidents crippling many young lives. Distal femoral fractures account for about $4 \%$ to $7 \%$ of all femoral fracture. The fracture characteristics which make these fractures difficult to treat include: osteoporosis, multiplanar articular injury, high degree of comminution, associated open wounds, internal derangement of knee including ligament and meniscal injuries and extensor mechanism injuries. ${ }^{1}$

Conservative methods met with problems like deformity, shortening, prolonged bed rest, knee stiffness, angulation, joint incongruity, mal-union, quadriceps wasting, knee instability and post-traumatic osteoarthritis. Earlier there was a great reluctance towards operative management of these fractures because of high incidence of infection, non-union, mal-union, inadequate fixation and lack of proper instruments, implant as well as antibiotics. In the present era fixation of fracture is the gold standard. ${ }^{2}$ The options for operative treatment are traditional plating techniques that require compression of the implant to the femoral shaft (blade plate, dynamic condylar screw, nonlocking condylar buttress plate), ante-grade nailing fixation, retrograde nailing, sub muscular locked internal fixation and external fixation. ${ }^{3}$ 
The locking compression plate is a single beam construct where the strength of fixation is equal to the sum of all screw-bone interfaces rather than a single screw's axial stiffness or pullout resistance as seen in unlocked plates. Its unique biomechanical function is based on splinting rather than compression resulting in rigid stabilization, avoidance of stress shielding and induction of callus formation. It increases the rigidity of fixation in osteoporotic bone or in the presence of peri-articular or juxta-articular fractures. The implant offers multiple points of fixed-angle contact between the plate and screws. ${ }^{4}$

\section{METHODS}

This study was carried out in department of orthopaedics, Sardar Patel Medical College and Trauma Centre, Bikaner. 90 patients of distal femoral fracture were operated using distal femoral locking compression plate between December 2015 to July 2017. All cases of closed distal femur fractures (AO type A and C) above 20 years of age were included in this study. Open fractures, pathological fractures, fractures with open physeal plate and those with neurovascular compromise were excluded from this study. Final assessment was done at 6 months by NEER score.

\section{Operative technique}

Patient was placed supine on a radiolucent table with a pillow under the knee, the entire injured extremity and ipsi-lateral iliac crest was painted and draped. Lateral approach was taken (Figure 1). Minimal Stripping of soft tissue was done and meticulous haemostasis was achieved. Quadriceps tendon and the patella are reflected medially to expose the lower end of the femur (Figure 2).

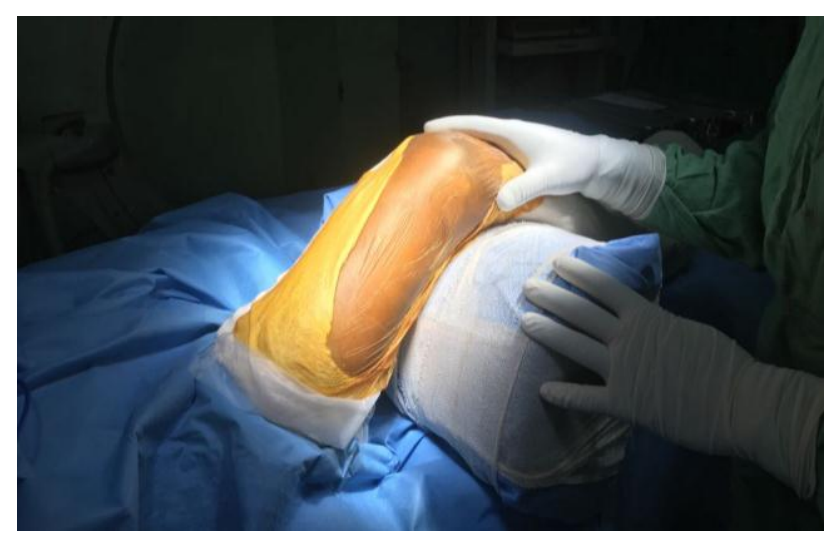

Figure 1: Positioning.

If shaft of the femur was found to be wedged between two condyles, traction was applied to disengage the fragments to achieve satisfactory reduction. A Steinmann pin was drilled into the lateral condyle. If needed, a similar pin was placed in the medial condylar fragment. Using these pins as joysticks, manipulation and reduction of the two major condylar fragments was done to restore the articular surface and patella-femoral groove. The condyles were fixed together with multiple $2 \mathrm{~mm}$ Kirschner wire temporarily.

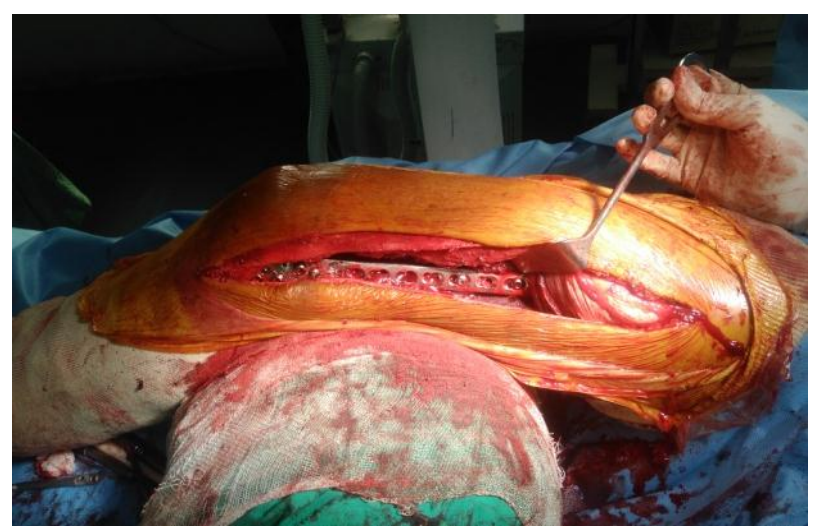

Figure 2: Application of plate.

Next step was to align femoral condyle with the shaft of femur. If fracture was unstable even after manual reduction inter-fragmentary screws were applied before application of plate. Appropriate size plate was chosen and applied over the lateral aspect of femur taking care of reduction. Reduction of the fracture was assisted keeping folded pillow under the knee which prevented posterior angulation of distal fragment with manual traction. Once the fracture is reduced, locking and non-locking screws were inserted to secure plate to the bone. Negative suction drain was inserted and closure was done layer by layer and compression bandage was applied.

\section{RESULTS}

A total of 90 patients were considered for the study. There were 64 males and 26 females with an average of 40.56 years (range 18 to 72 years). RTA was the commonest mode of injury accounting for $68.8 \%(62$ cases). Right sided fractures were recorded in $56 \%$ cases (50 cases) and left sided were $44 \%$ (40 cases).

Extra-articular fractures were encountered in 56.6\% (51 cases) and intra-articular fracture in $43.4 \%$ (39 cases). According to AO/ASIF classification (Table 1) most common fracture was A2 type (24.4\%). Most commonly used plate length was of 7 hole.

Table 1: Distribution by AO classification.

\begin{tabular}{|llll|}
\hline & AO type & $\begin{array}{l}\text { No. of } \\
\text { patients }\end{array}$ & $\%$ \\
\hline \multirow{3}{*}{ Extra-articular } & $\mathrm{A} 1$ & 20 & 22.2 \\
\cline { 2 - 4 } & $\mathrm{A} 2$ & 22 & 24.6 \\
\cline { 2 - 4 } Intra-articular & $\mathrm{A} 3$ & 09 & 10.0 \\
\hline & $\mathrm{C} 1$ & 16 & 17.7 \\
\cline { 2 - 4 } & $\mathrm{C} 2$ & 18 & 20.0 \\
\cline { 2 - 4 } & $\mathrm{C} 3$ & 05 & 04.4 \\
\hline & Total & 90 & 100 \\
\hline
\end{tabular}


Table 2: Distribution by duration of union.

\begin{tabular}{|lll|}
\hline Duration of union & No. of patients & $\%$ \\
\hline 12 week & 54 & 60.00 \\
\hline 16 week & 32 & 36.00 \\
\hline 24 week & 4 & 4.00 \\
\hline Total & 90 & 100 \\
\hline
\end{tabular}

Bridging callus appeared on radiograph in 54 cases at 8 week. Range of motion were $>120^{\circ}$ in 44 cases, $100-120^{\circ}$ in 34 cases. Average flexion at knee joint was $117^{0}$. Time of union was 12 week in 54 cases, 16 week in 32 cases and 24 week in 4 cases. Average time of union was 14.3 weeks (Table 2). Final outcome by NEER score was excellent in 44 cases, good in 32 cases, fair in 10 cases and poor in 4 cases (Table 3 ).

Table 3: Final outcome by Neer's score at 6 months.

\begin{tabular}{|lll|}
\hline Neer's score & No. of patients & $\%$ \\
\hline Excellent $(>\mathbf{8 5})$ & 44 & 48.8. \\
\hline Good (70-84) & 32 & 35.5 \\
\hline Fair $(\mathbf{5 0 - 6 9 )}$ & 10 & 11.1 \\
\hline Poor $(<\mathbf{5 0})$ & 04 & 04.4 \\
\hline Total & 90 & 100 \\
\hline
\end{tabular}

Figure 3: (A) Pre-op X-ray, (B) post-op 6 months and (C) follow up at 6 months.
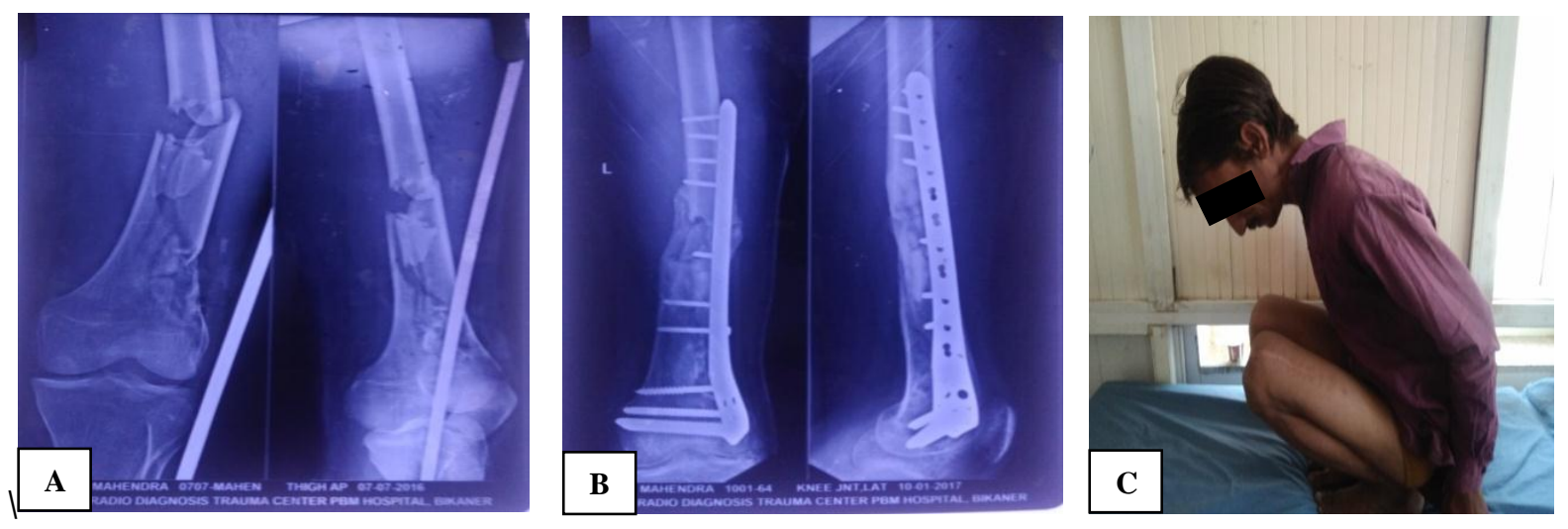

Figure 4: (A) Pre-op X-ray, (B) post-op 6 months and (C) follow up at 6 months.

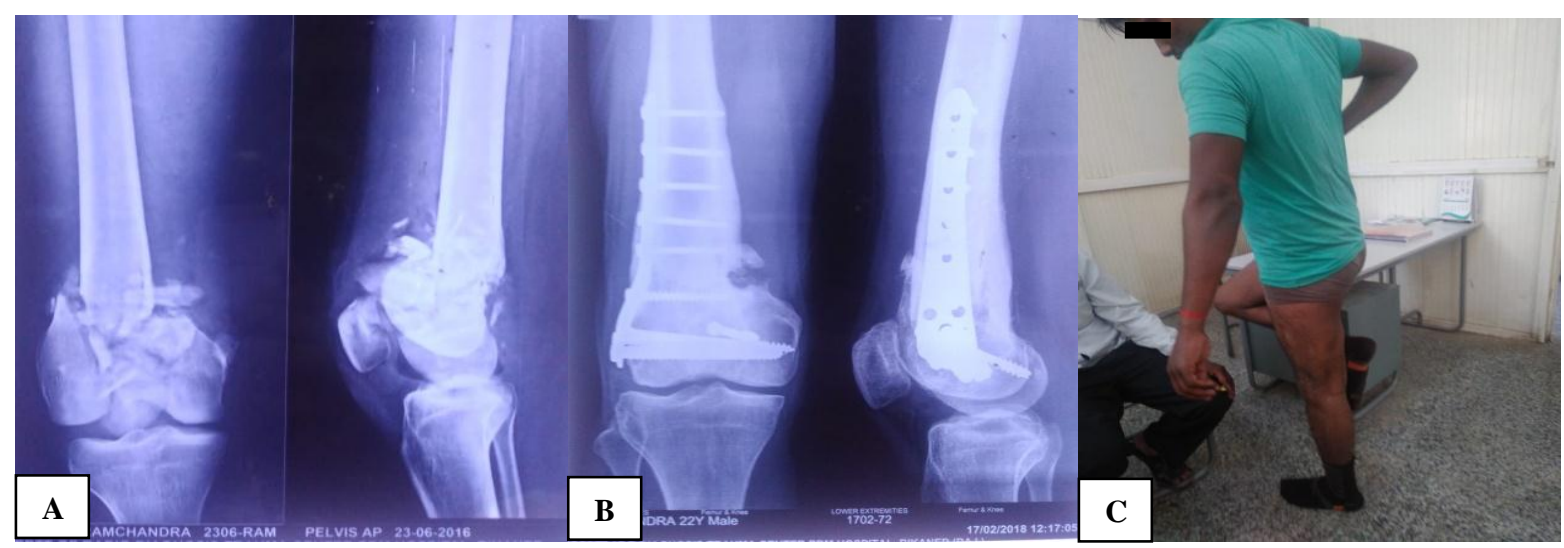

Figure 5: (A) Pre-op X-ray, (B) post-op 6 months and (C) follow up at 6 months. 


\section{DISCUSSION}

In our study 90 patients were included and the age ranged from 18 year to 72 year, the mean age of the patients was 40.56. This was lesser then the average age of 49 year in study conducted by Kregor et al. ${ }^{5}$ It was 54 year in study conducted by Schutz et al. ${ }^{6}$ In the study conducted by Deepak et al, it was 44 years. ${ }^{7}$ It was nearly equal (40.73) to study conducted by Dasaraiah et al. ${ }^{8}$

Male patients dominate the series because of nature of their outdoor activities, and rash driving, $71.1 \%$ male and $28.9 \%$ female were the cases in this study. In schutz et al study $57 \%$ male and $43 \%$ female were included. ${ }^{6}$ However this was in contrast to study conducted by Kregor et al who noted the incidence in 50\% male and $50 \%$ female. $^{5}$

In our series, road traffic accident accounted for highest incidence of these injuries (68\%), followed by fall from height $(20 \%)$, fall of heavy object $(8 \%)$. Similarly in study of Deepak et al RTA accounted for $60 \%$ of all injuries. ${ }^{7}$ Schutz et al also noted high incidence of road traffic accident in these fracture which accounted for $72 \%$ of cases included in their series. ${ }^{6}$

The incidence of fracture was more common on right side (50 cases) than left side (40 cases). In all these 90 cases distal femoral locking compression plate was done. In Yeap and Deepak et al study right side (7 cases) was more common then left $\left(4\right.$ cases). ${ }^{7}$ similar result were obtained in C.V. Dasraiah et al study (right -21 case, left 9 cases). ${ }^{8}$

AO type $\mathrm{A} \& \mathrm{C}$ fractures were included in our series, out of these A type(extra-articular) were 56.8\% (A1-22.2\%, $\mathrm{A} 2-24.6 \%, \mathrm{~A} 3-10 \%)$ and $\mathrm{C}$ type (intra-articular) were $42.2 \%$ (C1-17.8\%, C2-20.0\%, C3-04.4\%) similar results were obsereved by Deepak et $\mathrm{al}^{7}$ (type A-55\%, type C$45 \%$ ), Kregor et al ${ }^{5}$ (type A-50\%, type C-50) Schutz et al ${ }^{6}$ (type A-67\%, type C-33\%). The study conducted by Markmiller et al consisted of equal number type A and C fracture pattern. ${ }^{9}$

In our case series $24 \%$ cases had associated other injuries, head injury (4\%), blunt trauma abdomen (4\%), contralateral fracture leg bone $(4 \%)$, and contralateral fracture patella (4\%), fracture both bone forearam (4\%), fracture distal end radius (4\%). Most of these were due to road traffic accident. In our case series range of plate length was 5 hole to 13 hole. 7 (28\%) hole was most commonly used plate followed by 9 and 11 hole (24\% each). Four patients required 13 hole LCP for stable fixation. No patients required primary bone graft in our study similar results were found in the study conducted by Schandelmaier et al, Collinge et al reported a similar result in their study. ${ }^{10,11}$

As concerned with complication, 4 case had superficial infection $(4.4 \%)$ which was managed by regular dressing and antibiotics, 3 cases had varus mal-alignment, 3 cases had shortening of limb and stiffness in 4 cases. $3 \%$ cases had deep infection in Kregor et al study and 7\% cases had deep infection in Schutz et al study., ${ }^{5,6}$ Fankhauser et al had no malalignment cases in their study. ${ }^{12}$ Only 6\% cases had malalignment in Kregor et $\mathrm{al}^{5}$ and $9 \%$ cases in Deepak et al. ${ }^{7}$ No case required revision surgery and no cases of loose and broken implant was reported in our study compared to kregor et al study where $1.5 \%$ cases required revision surgery and Deeapk et al study where $9 \%$ cases required revision surgery. ${ }^{5,7}$ In weight and Colling et al $18.2 \%$ cases required implant removal due to pain. ${ }^{11}$

Average range of movement (ROM) of knee at 6 month was $1-117^{\circ}$ similar result were obtained by Schutz et al (Average flexion of knee $112^{\circ}$ ), Kregor et al study (ROM $-2-103^{\circ}$ ), Deepak et al study (ROM $1^{0}-107.7^{\circ}$ ), Weight and Colling et al study (ROM $5^{0}-114^{\circ}$ ), Schandelmaier et al study (Average flexion of knee $\left.-104^{\circ}\right)^{5-7,10,11}$

Follow up period in our case series was 6 month as compared to Deepak et al study (9.7month), Kregor et al study $(9$ month), Schandenmaier et al study (6 month). ${ }^{5,7,10}$

Average time of union in our cases were 14.3 week (Range 8-20 week) similar results were obtained in Kregor et al study (11 week) Fankhauser et al study (12 week). Duration of union reported by Deepak et al study is 18 week. ${ }^{5,7,12}$ In the study conducted by Wong et al, the time of union was 30 weeks. ${ }^{13}$

All cases were assessed by neer score and excellent to good results were obtained in $84.4 \%$ cases $(48.8 \%$ excellent and $35.5 \%$ good), $11 \%$ patients showed fair results and $4.4 \%$ cases showed poor result. ${ }^{14}$ Study of Deepak et al $72.7 \%$ cases showed excellent to good result evaluated by Schatzker score. ${ }^{7}$ Schandelmaier et al showed $73.9 \%$ cases had excellent to good result evaluated by neer criteria, Markmiller et al study showed $87.5 \%$ had excellent to good result evaluated by Lysholm criteria. ${ }^{9,10}$ Vishwanath et al reported excellent to good results in $78 \%$ cases using neer's criteria. ${ }^{15}$

\section{CONCLUSION}

Locking compression plate is an optimal tool for management of supracondylar fractures of femur. It provides rigid fixation in the region of femur, where a widening canal, thin cortices and frequently poor bone stock make fixation difficult. Surgical exposure for plate placement requires significantly less periosteal stripping and soft tissue exposure than that of normal plates. We recommend use of this implant in Type A and $\mathrm{C}$ and osteoporotic fractures.

To conclude, locking compression plate is an important armamentarium in treatment of fractures of distal end femur, especially when fracture is severely communited 
and in situations of osteoporosis. However a more comprehensive study with longer follow up periods is with special attention to the long term outcomes.

Funding: No funding sources

Conflict of interest: None declared

Ethical approval: The study was approved by the institutional ethics committee

\section{REFERENCES}

1. Wilson JN, Watson Jones high velocity injuries. Fractures and Joint Injuries. 6th edition. Edinburgh, New York: Churchill Livingstone; 1982: 1003 1070 .

2. Kregor PJ, Stannard J, Zlowodzki M, Cole PA, Alonso J. Distal femoral fracture fixation utilizing the Less Invasive Stabilization System (L.I.S.S.): the technique and early results. Injury. 2001;32(3):SC32-47.

3. Schütz M, Müller M, Regazzoni P, Höntzsch D, Krettek C, Van der Werken C, et al. Use of the Less Invasive Stabilization System (LISS) in patients with distal femoral (AO33) fractures: a prospective multicenter study. Arch Orthop Trauma Surg. 2005;125(2):102-8.

4. Hugh Owen Thomas. Quoted by Rockwood CA, Green DP. Fractures in adult. 4th edition, Volume II. 1996: 1972-1993.

5. Kregor PJ, Stannard JA, Zlowodzki M, Cole PA. Treatment of Distal Femur Fractures Using the Less Invasive Stabilization System: Surgical Experience and Early Clinical Results in 103 Fractures. J Orthop Trauma. 2004;18(8):509-20.

6. 3) Schütz M, Müller M, Regazzoni P, Höntzsch D, Krettek C, Van der Werken C, et al. Use of the Less Invasive Stabilization System (LISS) in patients with distal femoral (AO33) fractures: a prospective multicenter study. Arch Orthop Trauma Surg. 2005;125(2):102-8.
7. Yeap and Deepak. Distal Femoral Locking Compression Plate Fixation in Distal Femoral Fractures: Early Results. Malaysian Orthopaedic J. 1985;1:12-7.

8. Dasaraiah CV, Rao AS, Sahini SC. Surgical management of supracondylar femoral fracture by locking compression plate. IOSR. 2006;15:23-33.

9. Markmiller M, Allgoewer M, Sclmeider R. Distal femoral fractures. Manual der osteosynthese/ AO Technik. 1992;3:53-65.

10. Schandelmaier P, Partenheimer A, Koenemann B, Grun OA, Krettek C. Distal Femoral Fractures and LISS Stabilization. Injury. 2001;2:55-63.

11. Weight M, Collinge C. Early Results of the Less Invasive Stabilization System for Mechanically Unstable Fractures of the Distal Femur (AO/OTA Types A2, A3, C2, and C3). J Orthop Trauma. 2004;3:503-8.

12. Fankhauser F, Gruber G, Schippinger G, Boldin C, Hofer HP, Grechenig W, et al. Minimal-Invasive Treatment of Distal Femoral Fractures with the LISS (Less Invasive Stabilization System): A Prospective Study of 30 Fractures with a Follow Up of 20 Months. Acta Orthop Scand. 2004;1:56-60.

13. Wong MK, Leung F, Chow SP. Treatment of Distal Femoral Fractures in the Elderly Using a LessInvasive Plating Technique. Int Orthop. 2005;2:11720.

14. Neer CS, Grantham SA, Shelton ML. Supracondylar fracture of adult femur. JBJS. 1967;49:591-613.

15. Vishwanath C, Harish K, Gunnaiah KG, Kumar C. Surgical outcome of distal femur fracture by locking compression plate. IJOS. 2016;2:233-9.

Cite this article as: Khajotia BL, Shekhawat V, Chauhan S, Bhatiwal S. Clinical and radiological outcome of distal femoral fractures treated by distal femoral locking compression plate. Int J Res Orthop 2019;5:1083-7. 